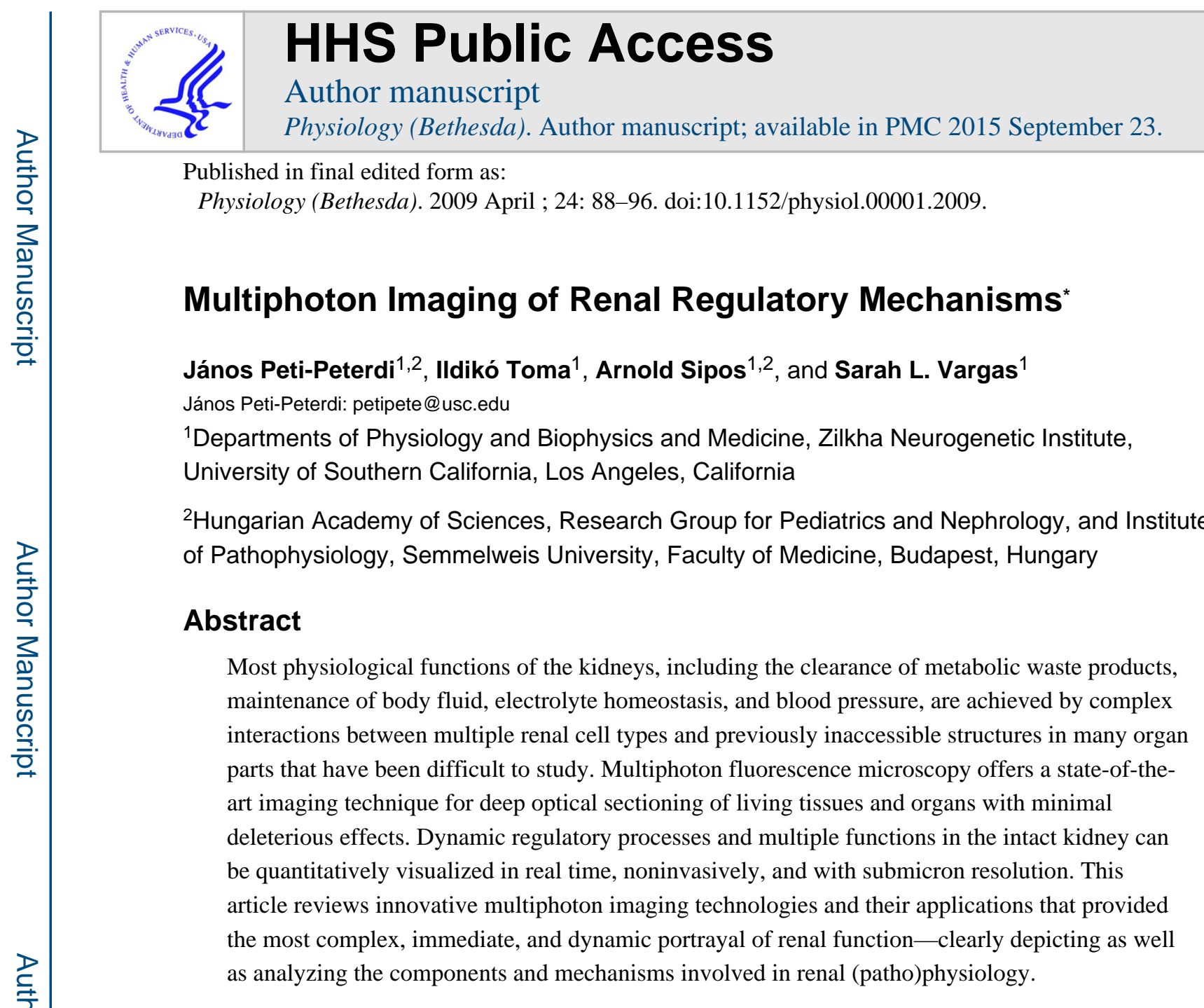

The old saying "seeing is believing" has driven many optical imaging applications in various fields of biomedical research, including renal physiology. Multiphoton microscopy (a term that denotes two- and three-photon excitation fluorescence microscopy) is an advanced confocal laser scanning fluorescence imaging technique that has proven especially useful for deep optical sectioning of living tissues. Multiphoton imaging can provide ultra-sensitive detection of fluorescent signals with submicron resolution, meaning that even intracellular organelles can be visualized in intact organs. The technology is based on the concept that the simultaneous absorption of two photons of equal energy can cause excitation of a fluorophore equivalent to the absorption of a single photon of double the energy $(7,74)$. Accordingly, multiphoton excitation uses infrared light in the 680- to 1,080-nm range in current commercial systems. In contrast, conventional confocal (one-photon) fluorescence imaging uses UV or visible lasers (193-694 nm). With multiphoton imaging, these longer (double or triple) wavelength photons (one-half or one-third of the energy) allow for deeper penetration into tissues with much less scattering and deleterious effects. Since multiphoton excitation occurs mainly at the focal plane, $100 \%$ of emitted (already confocal) fluorescence can be detected. In most multiphoton applications, there is no need for descanning and filtering the emitted fluorescence through pinholes as with conventional, one-photon

\footnotetext{
* This article contains supplementary files available online at the Physiology website.
} 
confocal imaging. Detailed descriptions of the technology and its advantages and disadvantages can be found elsewhere $(7,8,15,32,45,74)$.

Clear tissues like the brain can be easily visualized with multiphoton techniques in depths in the millimeter range $(8,15,22,74)$. In contrast, the use of this technology in the renal cortex has been limited to the initial 100-200 $\mu \mathrm{m}$ under the kidney surface mainly due to the highly light absorbing and scattering renal tissue structures $(32,45)$. Continuous improvements in optics, fluorescence detection, and laser technology, however, are helping us to go deeper in the intact kidney even with noninvasive or minimally invasive whole animal techniques. One example is the dispersion compensation (i.e., keeping laser pulses short, in the 100femtosecond range) that is now available in many commercial systems (for example, the Mai Tai DeepSee from Spectra-Physics/Newport and the Chameleon Vision from Coherent). Another improvement that facilitates deeper imaging is the significantly increased output power in new systems $(>4,000 \mathrm{~mW}$ in Chameleon Ultra-II or Vision from Coherent in contrast to $350 \mathrm{~mW}$ in the first Tsunami lasers from Spectra-Physics about 10 years ago), although one must be cognizant of potential damage to the sample due to heating effects of these high power lasers. As a result of these technical improvements and an important milestone discussed below, multiphoton visualization of mouse glomeruli is now possible in normal C57BL6 mice and does not require special animal strains with superficial glomeruli like the Munich-Wistar rat $(9,20,28)$.

This review focuses on the applications of multi-photon imaging in the intact kidney. We discuss recent advances in renal physiology and the imaging of complex renal regulatory mechanisms in or between the nephron and the vasculature, which were made possible by this imaging approach. We recommend this work for not only the basic or clinical research scientist but also as a visual aid for teaching graduate and medical students.

\section{Glomerular Structure and Function}

High-resolution optical sectioning through an entire living, intact glomerulus (diameter of $\sim 100 \mu \mathrm{m}$ ) has become possible with multiphoton microscopy, with the first in vitro (42) and in vivo applications (9) having been published in 2002. The initial studies provided impressive, high-quality images of the complex cell structure of the glomerulus and the juxtaglomerular apparatus (JGA) (42), as well as direct visualization of the glomerular filtration of iv-injected fluorescent markers $(9,10,32)$. Real-time changes in cell volume and cytosolic parameters (e.g., $\left[\mathrm{Ca}^{2+}\right]_{i}$ ) of otherwise inaccessible cell types, including the extra- and intra-glomerular mesangium, endothelium, and podocytes, were observed with this technology $(42,44-45)$. A few years later, the focus has shifted to quantitative imaging of basic renal functions, including the measurement of glomerular filtration rate (GFR). Using a number of water soluble, freely filtered, low molecular weight fluorescent markers, including a 10-kDa FITC-dextran (9, 10), Cascade blue (32), and Lucifer yellow (20), the process of glomerular filtration was visualized with high temporal resolution. This allowed the calculation of single nephron GFR (SNGFR) (20) using principles and techniques that were established earlier (4). A supplementary video file shows the renal clearance of the extracellular fluid marker Lucifer yellow (injected in a single iv bolus into the femoral vein) by glomerular filtration and its downstream movement in the proximal tubule (available 
online at the Physiology website) (from Ref. 20). Using two different molecular weight markers simultaneously injected iv and an optical ratiometric imaging approach, a technique has been developed by $\mathrm{Yu}$ and Molitoris for the rapid determination of GFR $(71,72)$ that has great potential for future use in clinical diagnostics.

Multiphoton imaging allowed both functional and morphological discoveries concerning the glomerular filtration barrier (GFB). FIGURE 1 demonstrates various applications both in vivo (FIGURE 1, A, B, AND D) and in vitro (FIGURE 1C) in various species. Importantly, with the development of multiphoton technology, the imaging of glomeruli is now possible not only in Munich-Wistar rats that are renowned for their surface glomeruli $(9,10,20,28)$ but also in wild-type C57BL6 mice that have glomeruli deeper under the surface. The imaging of glomeruli in the intact mouse kidney $~ 150-200 \mu \mathrm{m}$ under the surface is demonstrated in FIGURE 1B using previously described techniques (20) and a Leica TCS SP5 AOBS MP confocal microscope system (Leica Microsystems, Heidelberg, Germany) powered by a Chameleon Ultra-II mul-tiphoton laser (Coherent, Santa Clara, CA). This significant development opens up new possibilities for imaging kidney function in genetically modified small animals.

A recent, potentially paradigm-shifting finding in work by Russo et al. using multiphoton imaging was the observation of mass filtration of fluorophore-conjugated albumin in normal kidneys and its rapid endo-cytosis in the proximal tubule (55). This has led to the authors' assertion that the GFB normally leaks albumin at nephrotic levels and that this filtered albumin load is avidly bound and retrieved by cells of the proximal tubule (55). The issue is, however, highly debated (5), and multiphoton-based determination of the glomerular sieving coefficient for albumin that resulted in a value (0.02-0.04) that is 50 times greater than previously measured warrants future, careful review of the methodology. In contrast, another study found that glomerular permeability of rhodamine-conjugated 70-kDa dextran (only slightly larger than albumin) was minimal even in STZ-diabetic, hyperfiltering glomeruli as opposed to the highly dextran-permeable sclerotic glomeruli, the likely source of diabetic proteinuria (20).

Ultrastructural reconstruction of the podocyte and the glomerulus by Neal and colleagues (34) resulted in the exciting anatomical discovery of the subpodocyte space (SPS). The SPS was identified as the labyrinthine space between the underside of podocyte cell body/ primary processes and the foot processes and was proposed to be a new layer of the GFB (34). Morphometric measurements suggested highly significant restriction to flow by the SPS $(34,35)$, a finding that was later confirmed functionally in the intact glomerulus and kidney by multiphoton imaging studies (56). Using methods demonstrated in FIGURE 1, C AND D, it was found that rhodamine-conjugated 10-kDa dextran, but not the low-weight molecule Lucifer yellow, accumulated in SPS-covered regions of the GFB (56). The SPSmediated resistance to flow adds more complexity to the glomerular filtration process and further suggests the important physiological role of podocytes in the regulation of GFR. FIGURE 1, C AND D, provides examples of how the podocyte cell body, main processes, and intracellular vesicles can be visualized in the intact glomerulus and kidney. The drawings in FIGURE 1E (from Ref. 56) illustrate the two regions of GFB either covered by the SPS or not (naked region). 
Real-time multiphoton imaging of the iv injected extracellular fluid marker Lucifer yellow was also instrumental in the direct visualization of the bulk fluid flow in the JGA interstitium (54) originally proposed and described by Rosivall $(52,53)$. Ultrafiltration of plasma through the fenestrated endothelium in the terminal renin-positive segment of the afferent arteriole $(52,53)$ was further confirmed by using this imaging approach $(54)$. It has been suggested that this dynamic fluid flow in the JGA may help filter the released renin into the renal interstitium (endocrine function) or perhaps modulate the concentration of chemical mediators in the JGA interstitium that are important in the regulation of renal and glomerular hemodynamics (54).

\section{Tubular Transport}

Multiphoton microscopy has been used to study various tubular functions including proximal tubule endo-cytosis of gentamicin (9), folic acid (57), siRNA (33), and albumin $(32,55)$, as well as tubular secretion (63), protein expression (64), cyst development $(9,63)$, and apoptosis (9). FIGURE 2, A-D, shows time-lapse mul-tiphoton imaging of iv-injected siRNA uptake in rat proximal and distal nephron segments, illustrating the feasibility of using the siRNA technique for efficient gene silencing in all nephron segments. With the help of low or intermediate molecular weight markers that were injected iv (Lucifer yellow, 10- to 70-kDa dextran), tubular fluid flow rates, the renal concentrating-diluting mechanism, and the effects of diuretics were visualized and quantified $(9,20,32)$.

Multiphoton microscopy allowed real-time visualization of cytosolic variables (e.g., intracellular ion concentrations) in intact tubular epithelia in vivo such as $\mathrm{pH}$ and $\left[\mathrm{Ca}^{2+}\right]_{\mathrm{i}}$ (61). One caveat when loading cells in vivo with the widely used acetoxymethylester (AM) forms of fluorophores is the significant esterase activity of plasma. AM dyes (when used in vitro) can quickly enter the cell across the plasma membrane and get trapped after cleavage of the AM group by intracellular esterases. When injected iv, however, plasma enzymes can rapidly cleave the AM groups, resulting in the formation of the free, cell-impermeable form before reaching the target cells, thereby making cell loading very inefficient (18). One possible solution is the targeted bulk loading of fluorescent indicators by direct injection under the renal capsule, similar to the multi-cell bolus loading (MCBL) technique developed for multiphoton imaging of the brain in vivo (12). This method was successful for visualizing real-time changes in proximal tubule cell $\mathrm{pH}$ (important to study bicarbonate reabsorption) and $\left[\mathrm{Ca}^{2+}\right]_{i}(61)$. Here, we show the loading of proximal and distal tubule cells with the calcium fluorophore Rhod-2 AM injected under the renal capsule (FIGURE 2, E AND F) using previously described methods $(20,61)$. The use of this red calcium fluorophore was preferred over green dyes (like Fluo-4) due to the low overlap of its emission with the significant renal tissue autofluorescence. In all nephron segments, regular oscillations in $\left[\mathrm{Ca}^{2+}\right]_{\mathrm{i}}$ were observed with one slow $(\sim 20-40 \mathrm{mHz})$ and one fast $(100-200$ $\mathrm{mHz}$ ) component (FIGURE $2 \mathrm{G}) .\left[\mathrm{Ca}^{2+}\right]_{\mathrm{i}}$ oscillations were most likely functionally associated with variations in tubular fluid flow rate due to tubu-loglomerular feedback and the myogenic mechanism of the afferent arteriole that have the same characteristics $(16,20$, 30), since the proximal tubule diameter showed similar, phase-matched oscillations (FIGURE $2 \mathrm{G}$ ). A supplementary video file shows proximal tubule $\left[\mathrm{Ca}^{2+}\right]$ oscillations in the 
intact kidney from the same in vivo preparation as shown in the still image of FIGURE 2F (see supplemental video at the Physiology website).

\section{Tubulo-vascular Interactions}

One of the earliest applications of multiphoton imaging in renal tissues was the visualization of the juxta-glomerular apparatus (JGA) (42). The multiphoton imaging approach proved to be very useful for the study of this hardly accessible, highly heterogeneous cell complex that is one of the most important regulatory sites of renal salt and water conservation as well as blood pressure maintenance (19-21, 25-27, 40-42, 44, 45, 54, 56, 61). The main JGA functions include the high distal tubular $[\mathrm{NaCl}]$-induced afferent arteriolar vasoconstriction that controls GFR, renal blood flow [tubuloglomerular feedback (TGF)], and the low tubular $[\mathrm{NaCl}]$-induced renin release that activates the renin-angiotensin system (RAS) (59). Numerous details of these important physiological mechanisms were observed with multiphoton microscopy using the in vitro dissected and microperfused JGA model (FIGURE 3, A-D). Supplementary video files are available in the online version of this article that demonstrate in this living JGA preparation the TGF and renin release mechanisms (see supplemental files online at the Physiology website) (from Refs. 40, 44). Real-time visualization of the JGA revealed that increased salt content and/or tubular fluid flow in the distal tubule at the point of the macula densa (the sensory element of JGA) triggers mesangial and vascular smooth muscle cell $\left[\mathrm{Ca}^{2+}\right]_{\mathrm{i}}$ elevations and cell contractions $(44,45)$. The TGF calcium wave (illustrated in FIGURE 3D) and vasoconstriction propagated from the MD region toward both the proximal afferent and efferent arterioles and all cells of the glomerulus at a rate of $\sim 12 \mu \mathrm{m} / \mathrm{s}$ (44). The TGF calcium wave was mediated by extracellular ATP $(44)$, supporting earlier findings $(1,17,38)$ that ATP itself is directly involved in TGF and not simply through its breakdown to adenosine $(2,3,48,62)$. Using ANNINE-6 [a new, highly sensitive ultrafast and highly cell membrane-specific voltage-sensing dye (FIGURE 3C)], a recent study observed a much faster propagating electrotonic vascular TGF signal as well (31), a mechanism that has been implicated in nephron synchronization (31). These conducted vascular signals nicely demonstrate the important role of intercellular communication in the JGA, which involves not only extracellular chemical mediators $(24,58)$ but gap junctions as well $(44,49,69,70)$. An interesting new development concerning con-nexins, the building blocks of gap junctions, is the possibility of connexin hemichannels mediating the release of ATP $(44,67)$.

Multiphoton imaging has also helped to visualize morphological changes of the JGA in realtime and in four dimensions. For example, cell volume of the macula densa was found to be a good indicator of tubular salt content $(29,42)$, and changes in cell volume were suggested as part of the macula densa salt-sensing mechanism leading to the generation of renin release signals (14). However, tubular salt-dependent macula densa cell swelling or shrinkage was also dependent on simultaneous changes in tubular fluid osmolality (25). Also, a recent elegant study by Komlosi et al. found regular oscillations in $\left[\mathrm{Ca}^{2+}\right]_{\mathrm{i}}$ in the cortical thick ascending limb around the macula densa (26), suggesting that, in addition to the classic tubulo-vascular contact in the JGA, this "perimacular" region also participates in the control of afferent and efferent arteriolar resistance $(26,27)$. Another tubulo-vascular 
control mechanism exists between the connecting tubule segment and the proximal part of the afferent arteriole (50).

The complexity of tubulo-vascular interactions can be visualized on the intact, whole organ level using multiphoton imaging (20). A supplementary video file in the online version of this article demonstrates the nonlinear nature of glomerular and tubular functions (available at the Physiology website) (from Ref. 20). Due to the myogenic and TGF mechanisms, regular periods of glomerular contraction-relaxation were observed, resulting in oscillations of GFR and tubular fluid flow rate. The oscillations in proximal and distal tubular fluid flow showed similar characteristics (slow and fast components) as described earlier (FIGURE $2 \mathrm{G})(16,30)$. Alterations in urinary concentrating and diluting mechanisms and the effects of furosemide causing diuresis, enlargement of collecting ducts that resulted in the compression of peritubular capillaries were also directly visualized $(20,60)$. The latter is consistent with the paradoxical, preglomerular vasodilator but renal blood flow-reducing effect of furosemide (39).

\section{The Intra-renal Renin-Angiotensin System}

Heterogeneity of cortical renin synthesis in the kidney provides another good example of the advantages of this direct imaging approach. In addition to the JGA, which is the classic anatomical site of renin synthesis, significant amounts of renin were recently found in principal cells of the connecting tubule and the collecting duct (CD) $(21,46,47,51)$. CD renin synthesis was particularly robust in pathophysiological states associated with high RAS activity, such as diabetes and renovascular hypertension $(21,46,47)$. Also, the CD was identified as the major source of prorenin synthesis in diabetes (21). Interestingly, angiotensin II (ANGII) differentially regulates the synthesis of JGA (inhibition) and CD (stimulation) renin $(21,46,47)$, making the conventional molecular studies (using whole kidney or whole cortical tissue samples) somewhat problematic. However, in vivo imaging of the two main intra-renal locations of (pro)renin synthesis is possible using multiphoton microscopy as shown in FIGURE 4, A AND B. Quinacrine, a nonspecific aci-dotropic fluorophore that labels renin granules very intensely has been used successfully to visualize JGA renin content both in vitro (FIGURE 3B) $(40,45)$ and in vivo (FIGURE 4A) $(20,61$, 65 ). It should be noted, however, that quinacrine is also a weak stain of all acidic organelles, including lysosomes and cell nuclei. Therefore, it must be used carefully and only with imaging applications that allow direct acquisition of renin granules (based on location), and separation from background fluorescence (in lysosomes, etc.) as shown in FIGURE 4. Colocalization of the intravital quinacrine fluorescence with immunohistochemical labeling for renin validates the use of this dye to label both JGA and CD renin granules (FIGURE 4, C AND D). According to the recent findings of immense $C D$ (pro)renin synthesis in diabetes (21) (FIGURE 4B), CD prorenin may be released to cause systemic or local pathological actions at the recently identified and characterized (pro)renin receptor $(6,36,37)$, either as a signaling molecule or as a source of locally produced ANGII. This would be consistent with the existence of a local distal tubular RAS (51) and with its possible regulatory effects on salt reabsorption $(23,43)$. 
Using the multiphoton imaging approach, it is now possible to directly visualize not only renin granular content and release but also the enzyme activity of renin in intact renal tissues (FIGURE 5). Several fluorescence resonance energy transfer (FRET)-based fluorogenic renin substrates have been recently developed by various companies (Invitrogen, AnaSpec, Cayman Chemical, etc.) and contain a pair of donor-acceptor fluorophores connected by a sequence (decapeptide) of rodent angiotensinogen, including the renin cleavage site at the Leu-Leu bond (Leu-Val in humans). Using the newest generation of highly sensitive protease FRET assays (FIGURE 5), in the absence of renin activity, the donor (5-FAM) fluorescence is quenched by the acceptor molecule (QXL 520) due to their close proximity and fluorescence resonance energy transfer (FRET) between them. However, upon cleavage into two separate fragments by rat or mouse renin, the fluorescence of 5-FAM is recovered and can be monitored. This fluorescence-based technique permits real-time measurement of renin activity, does not utilize radioactivity, and is conveniently performed within minutes, as opposed to conventional renin assays using radioimmuno methods.

For future applications, this imaging approach can be very helpful to study the intra-renal RAS in (patho)physiological conditions such as diabetes. Although it is well established that RAS activity is high in diabetes (13), it has been difficult to measure increased ANGII formation or activity in the diabetic kidney using conventional molecular techniques (73). This new fluo-rogenic renin substrate in conjunction with multipho-ton imaging can help detect renin enzymatic activity and locally produced, sequestered ANG peptides, for example in the JGA as shown in FIGURE 5B. Also, the importance of RAS activation in several metabolic diseases, including diabetes, metabolic syndrome, and hyper-uricemia, has been recognized $(11,13)$. The recent localization of the metabolic receptor GPR91 in the (juxta)glomerular vasculature and the macula densa provided a new, direct link between high glucose levels and renin release from the JGA leading to RAS activation $(66,68)$. GPR91-dependent variations in JGA renin content were visualized in control and diabetic kidneys with multiphoton microscopy (66). This imaging approach can be used to monitor and study the complex mechanisms of RAS activation in many disease models.

\section{Supplementary Material}

Refer to Web version on PubMed Central for supplementary material.

\section{Acknowledgments}

This work was supported by National Institute of Diabetes and Digestive and Kidney Diseases Grants DK-64324 and DK-74754, and American Heart Association (AHA) Established Investigator Award 0640056N to J. PetiPeterdi. A. Sipos was supported by an AHA Western Affiliate Postdoctoral Research Fellowship during these studies.

\section{References}

1. Bell PD, Lapointe JY, Sabirov R, Hayashi S, Peti-Peterdi J, Manabe K, Kovacs G, Okada Y. Macula densa cell signaling involves ATP release through a maxi anion channel. Proc Natl Acad Sci USA. 2003; 100:4322-4327. [PubMed: 12655045]

2. Brown R, Ollerstam A, Johansson B, Skøtt O, Gebre-Medhin S, Fredholm B, Persson AE. Abolished tubuloglomerular feedback and increased plasma renin in adenosine A1 receptor- 
deficient mice. Am J Physiol Regul Integr Comp Physiol. 2001; 281:R1362-R1367. [PubMed: 11641103]

3. Castrop H, Huang Y, Hashimoto S, Mizel D, Hansen P, Theilig F, Bachmann S, Deng C, Briggs J, Schnermann J. Impairment of tubuloglomerular feedback regulation of GFR in ecto-5'nucleotidase/CD73-deficient mice. J Clin Invest. 2004; 114:634-642. [PubMed: 15343381]

4. Chou CL, Marsh DJ. Measurement of flow rate in rat proximal tubules with a nonobstructing optical method. Am J Physiol Renal Fluid Electrolyte Physiol. 1987; 253:F366-F371.

5. Christensen EI, Birn H, Rippe B, Maunsbach AB. Controversies in nephrology: renal albumin handling, facts, and artifacts! Kidney Int. 2007; 72:1192-1194. [PubMed: 17805237]

6. Danser AH, Deinum J. Renin, prorenin and the putative (pro)renin receptor. Hypertension. 2005; 46:1069-1076. [PubMed: 16186442]

7. Denk W, Strickler J, Webb WW. Two-photon laser scanning fluorescence microscopy. Science. 1990; 248:73-76. [PubMed: 2321027]

8. Denk W, Svoboda K. Photon upmanship: why multiphoton imaging is more than a gimmick. Neuron. 1997; 18:351-357. [PubMed: 9115730]

9. Dunn KW, Sandoval RM, Kelly KJ, Dagher PC, Tanner GA, Atkinson SJ, Bacallao RL, Molitoris BA. Functional studies of the kidney of living animals using multicolor two-photon microscopy. Am J Physiol Cell Physiol. 2002; 283:C905-C916. [PubMed: 12176747]

10. Dunn KW, Sandoval RM, Molitoris BA. Intravital imaging of the kidney using multiparameter multiphoton microscopy. Nephron Exp Nephrol. 2003; 94:e7-e11. [PubMed: 12806182]

11. Feig DI, Kang DH, Johnson RJ. Uric acid and cardiovascular risk. N Engl J Med. 2008; 359:18111821. [PubMed: 18946066]

12. Garaschuk O, Milos RI, Konnerth A. Targeted bulk-loading of fluorescent indicators for twophoton brain imaging in vivo. Nat Protoc. 2006; 1:380-386. [PubMed: 17406260]

13. Gurley SB, Coffman TM. The renin-angiotensin system and diabetic nephropathy. Semin Nephrol. 2007; 27:144-152. [PubMed: 17418683]

14. Hanner F, Chambrey R, Bourgeois S, Meer E, Mucsi I, Rosivall L, Shull GE, Lorenz JN, Eladari $\mathrm{D}$, Peti-Peterdi J. Increased renal renin content in mice lacking the $\mathrm{Na}^{+} / \mathrm{H}^{+}$exchanger NHE2. Am J Physiol Renal Physiol. 2008; 294:F937-F944. [PubMed: 18287398]

15. Helmchen F, Denk W. Deep tissue two-photon microscopy. Nat Methods. 2005; 2:932-940. [PubMed: 16299478]

16. Holstein-Rathlou NH, Leyssac PP. TGF-mediated oscillations in proximal intratubular pressure: differences between spontaneously hypertensive rats and Wistar-Kyoto rats. Acta Physiol Scand. 1986; 126:333-339. [PubMed: 3962682]

17. Inscho EW, Cook AK, Imig JD, Vial C, Evans RJ. Physiological role for P2X1 receptors in renal microvascular autoregulatory behavior. J Clin Invest. 2003; 112:1895-905. [PubMed: 14679185]

18. Jobsis PD, Rothstein EC, Balaban RS. Limited utility of acetoxymethyl (AM)-based intracellular delivery systems, in vivo: interference by extracellular esterases. J Microsc. 2007; 226:74-81. [PubMed: 17381712]

19. Kang JJ, Toma I, Sipos A, McCulloch F, Peti-Peterdi J. Imaging the renin-angiotensin system: an important target of anti-hypertensive therapy. Adv Drug Delivery Res. 2006; 58:824-833.

20. Kang JJ, Toma I, Sipos A, McCulloch F, Peti-Peterdi J. Quantitative imaging of basic functions in renal (patho)physiology. Am J Physiol Renal Physiol. 2006; 291:F495-F502. [PubMed: 16609147]

21. Kang JJ, Toma I, Sipos A, Meer EJ, Vargas SL, Peti-Peterdi J. The collecting duct is the major source of prorenin in diabetes. Hypertension. 2008; 51:1597-1604. [PubMed: 18413493]

22. Kleinfeld D, Mitra PP, Helmchen F, Denk W. Fluctuations and stimulus-induced changes in blood flow observed in individual capillaries in layers 2 through 4 of rat neocortex. Proc Natl Acad Sci USA. 1998; 95:15741-15746. [PubMed: 9861040]

23. Komlosi P, Fuson AL, Fintha A, Peti-Peterdi J, Rosivall L, Warnock DG, Bell PD. Angiotensin I conversion to angiotensin II stimulates cortical collecting duct sodium transport. Hypertension. 2003; 42:195-199. [PubMed: 12835330] 
24. Komlosi P, Fintha A, Bell PD. Renal cell-to-cell communication via extracellular ATP. Physiology. 2005; 20:86-90. [PubMed: 15772296]

25. Komlosi P, Fintha A, Bell PD. Unraveling the relationship between macula densa cell volume and luminal solute concentration/osmolality. Kidney Int. 2006; 70:865-871. [PubMed: 16820788]

26. Komlosi P, Banizs B, Fintha A, Steele S, Zhang ZR, Bell PD. Oscillating cortical thick ascending limb cells at the juxtaglomerular apparatus. J Am Soc Nephrol. 2008; 19:1940-1946. [PubMed: 18562570]

27. Komlosi P, Bell PD, Zhang ZR. Tubuloglomerular feedback mechanisms in nephron segments beyond the macula densa. Curr Opin Nephrol Hypertens. 2009; 18:57-62. [PubMed: 19077690]

28. Li B, Yao J, Kawamura K, Oyanagi-Tanaka Y, Hoshiyama M, Morioka T, Gejyo F, Uchiyama M, Oite T. Real-time observation of glomerular hemodynamic changes in diabetic rats: effects of insulin and ARB. Kidney Int. 2004; 66:1939-1948. [PubMed: 15496165]

29. Liu R, Persson AE. Simultaneous changes of cell volume and cytosolic calcium concentration in macula densa cells caused by alterations of luminal $\mathrm{NaCl}$ concentration. J Physiol. 2005; 563:895901. [PubMed: 15661823]

30. Marsh DJ, Sosnovtseva OV, Chon KH, Holstein-Rathlou NH. Nonlinear interactions in renal blood flow regulation. Am J Physiol Regul Integr Comp Physiol. 2005; 288:R1143-R1159. [PubMed: 15677526]

31. Marsh DJ, Toma I, Sosnovtseva OV, Peti-Peterdi J, Holstein-Rathlou NH. Electrotonic vascular signal conduction and nephron synchronization. Am J Physiol Renal Physiol. In press.

32. Molitoris BA, Sandoval RM. Intravital multiphoton microscopy of dynamic renal processes. Am J Physiol Renal Physiol. 2005; 288:F1084-F1089. [PubMed: 15883167]

33. Molitoris BA, Sandoval RM. Pharmacophotonics: utilizing multi-photon microscopy to quantify drug delivery and intracellular trafficking in the kidney. Adv Drug Delivery Res. 2006; 58:809823.

34. Neal CR, Crook H, Bell E, Harper SJ, Bates DO. Three-dimensional reconstruction of glomeruli by electron microscopy reveals a distinct restrictive urinary subpodocyte space. J Am Soc Nephrol. 2005; 16:1223-1235. [PubMed: 15829713]

35. Neal CR, Muston PR, Njegovan D, Verrill R, Harper SJ, Deen WM, Bates DO. Glomerular filtration into the subpodocyte space is highly restricted under physiological perfusion conditions. Am J Physiol Renal Physiol. 2007; 293:F1787-F1798. [PubMed: 17715264]

36. Nguyen G, Delarue F, Burckle C, Bouzhir L, Giller T, Sraer JD. Pivotal role of the renin/prorenin receptor in angiotensin II production and cellular responses to renin. J Clin Invest. 2002; 109:1417-1427. [PubMed: 12045255]

37. Nguyen G. Increased cyclooxygenase-2, hyperfiltration, glomerulosclerosis, and diabetic nephropathy: put the blame on the (pro)renin receptor? Kidney Int. 2006; 70:618-620. [PubMed: 16900219]

38. Nishiyama A, Navar LG. ATP mediates tubuloglomerular feedback. Am J Physiol Regul Integr Comp Physiol. 2002; 283:R273-R275. [PubMed: 12069954]

39. Oppermann M, Hansen PB, Castrop H, Schnermann J. Vasodilatation of afferent arterioles and paradoxical increase of renal vascular resistance by furosemide in mice. Am J Physiol Renal Physiol. 2007; 293:F279-F287. [PubMed: 17494095]

40. Peti-Peterdi J, Fintha A, Fuson AL, Tousson A, Chow RH. Real-time imaging of renin release in vitro. Am J Physiol Renal Physiol. 2004; 287:F329-F335. [PubMed: 15082450]

41. Peti-Peterdi J, Kang JJ, Toma I. Activation of the renal renin-angiotensin system in diabetes: new concepts. Nephrol Dial Transplant. 2008; 23:3047-3049. [PubMed: 18644796]

42. Peti-Peterdi J, Morishima S, Bell PD, Okada Y. Two-photon excitation fluorescence imaging of the living juxtaglomerular apparatus. Am J Physiol Renal Physiol. 2002; 283:F197-F201. [PubMed: 12060602]

43. Peti-Peterdi J, Warnock DG, Bell PD. Angiotensin II directly stimulates ENaC activity in the cortical collecting duct via AT(1) receptors. J Am Soc Nephrol. 2002; 13:1131-1135. [PubMed: 11960999]

44. Peti-Peterdi J. Calcium wave of tubuloglomerular feedback. Am J Physiol Renal Physiol. 2006; 291:F473-F480. [PubMed: 16495210] 
45. Peti-Peterdi J. Multiphoton imaging of renal tissues in vitro. Am J Physiol Renal Physiol. 2005; 288:F1079-F1083. [PubMed: 15883166]

46. Prieto-Carrasquero MC, Harrison-Bernard LM, Kobori H, Ozawa Y, Hering-Smith KS, Hamm LL, Navar LG. Enhancement of collecting duct renin in angiotensin II-dependent hypertensive rats. Hypertension. 2004; 44:223-229. [PubMed: 15226276]

47. Prieto-Carrasquero MC, Botros FT, Pagan J, Kobori H, Seth DM, Casarini DE, Navar LG. Collecting duct renin is upregulated in both kidneys of 2-kidney, 1-clip goldblatt hypertensive rats. Hypertension. 2008; 51:1590-1596. [PubMed: 18426992]

48. Ren Y, Garvin JL, Liu R, Carretero OA. Role of macula densa adenosine triphosphate (ATP) in tubuloglomerular feedback. Kidney Int. 2004; 66:1479-1485. [PubMed: 15458441]

49. Ren Y, Carretero OA, Garvin JL. Role of mesangial cells and gap junctions in tubuloglomerular feedback. Kidney Int. 2002; 62:525-531. [PubMed: 12110013]

50. Ren Y, Garvin JL, Liu R, Carretero OA. Crosstalk between the connecting tubule and the afferent arteriole regulates renal microcirculation. Kidney Int. 2007; 71:1116-1121. [PubMed: 17361114]

51. Rohrwasser A, Morgan T, Dillon HF, Zhao L, Callaway CW, Hillas E, Zhang S, Cheng T, Inagami T, Ward K, Terreros DA, Lalouel JM. Elements of a paracrine tubular renin angiotensin system along the entire nephron. Hypertension. 1999; 34:1265-1274. [PubMed: 10601129]

52. Rosivall L, Rázga Z, Mirzahosseini S, Tornóci L. Endothelial permeability of the afferent arteriole and its changes as the result of alteration in the activity of the renin-angiotensin system. J Am Soc Nephrol. 1999; 10:S172-S177. [PubMed: 9892159]

53. Rosivall L. Morphology and function of the distal part of the afferent arteriole. Kidney Int. 1990; 30:S10-S15.

54. Rosivall L, Mirzahosseini S, Toma I, Sipos A, Peti-Peterdi J. Fluid flow in the juxtaglomerular inter-stitium visualized in vivo. Am J Physiol Renal Physiol. 2006; 291:F1241-F1247. [PubMed: 16868308]

55. Russo LM, Sandoval RM, McKee M, Osicka TM, Collins AB, Brown D, Molitoris BA, Comper WD. The normal kidney filters nephrotic levels of albumin retrieved by proximal tubule cells: retrieval is disrupted in nephrotic states. Kidney Int. 2007; 71:504-513. [PubMed: 17228368]

56. Salmon AH, Toma I, Sipos A, Muston PR, Harper SJ, Bates DO, Neal CR, Peti-Peterdi J. Evidence for restriction of fluid and solute movement across the glomerular capillary wall by the subpodocyte space. Am J Physiol Renal Physiol. 2007; 293:F1777-F1786. [PubMed: 17804486]

57. Sandoval RM, Kennedy MD, Low PS, Molitoris BA. Uptake and trafficking of fluorescent conjugates of folic acid in intact kidney determined using intravital two-photon microscopy. Am J Physiol Cell Physiol. 2004; 287:C517-C526. [PubMed: 15102609]

58. Schnermann J, Levine DZ. Paracrine factors in tubuloglomerular feedback: adenosine, ATP, and nitric oxide. Annu Rev Physiol. 2003; 65:501-529. [PubMed: 12208992]

59. Schnermann, J.; Briggs, JP. Function of the juxtaglomerular apparatus: control of glomerular hemodynamics and renin secretion. In: Alpern, RJ.; Hebert, SC., editors. The Kidney Physiology and Pathophysiology. London: Elsevier Academic Press; 2008. p. 589-626.

60. Simeoni M, Boyde A, Shirley DG, Capasso G, Unwin RJ. Application of red laser video-rate scanning confocal microscopy to in vivo assessment of tubular function in the rat: selective action of diuretics on tubular diameter. Exp Physiol. 2004; 89:181-185. [PubMed: 15123547]

61. Sipos A, Toma I, Kang JJ, Rosivall L, Peti-Peterdi J. Advances in renal (patho)physiology using multiphoton microscopy. Kidney Int. 2007; 72:1188-1191. [PubMed: 17667980]

62. Sun D, Samuelson LC, Yang T, Huang Y, Paliege A, Saunders T, Briggs J, Schnermann J. Mediation of tubuloglomerular feedback by adenosine: evidence from mice lacking adenosine 1 receptors. Proc Natl Acad Sci USA. 2001; 98:9983-9988. [PubMed: 11504952]

63. Tanner GA, Sandoval RM, Dunn KW. Two-photon in vivo microscopy of sulfonefluorescein secretion in normal and cystic rat kidneys. Am J Physiol Renal Physiol. 2004; 286:F152-F160. [PubMed: 12965895]

64. Tanner GA, Sandoval RM, Molitoris BA, Bamburg JR, Ashworth SL. Micropuncture gene delivery and intravital two-photon visualization of protein expression in rat kidney. Am J Physiol Renal Physiol. 2005; 289:F638-F643. [PubMed: 15886277] 
65. Toma I, Kang JJ, Peti-Peterdi J. Imaging renin content and release in the living kidney. Nephron Physiol. 2006; 103:71-74.

66. Toma I, Kang JJ, Sipos A, Vargas S, Bansal E, Hanner F, Meer E, Peti-Peterdi J. Succinate receptor GPR91 provides a direct link between high glucose levels and renin release in murine and rabbit kidney. J Clin Invest. 2008; 118:2526-2534. [PubMed: 18535668]

67. Toma I, Bansal E, Meer EJ, Kang JJ, Vargas SL, Peti-Peterdi J. Connexin 40 and ATP-dependent intercellular calcium wave in renal glomerular endothelial cells. Am J Physiol Regul Integr Comp Physiol. 2008; 294:R1769-R1776. [PubMed: 18401004]

68. Vargas SL, Toma I, Kang JJ, Meer E, Peti-Peterdi J. Succinate receptor (GPR91) activation in macula densa cells causes renin release. J Am Soc Nephrol. In press.

69. Wagner C. Function of connexins in the renal circulation. Kidney Int. 2008; 73:547-555. [PubMed: 18075497]

70. Yao J, Oite T, Kitamura M. Gap junctional intercellular communication in the juxtaglomerular apparatus. Am J Physiol Renal Physiol. In press.

71. Yu W, Sandoval RM, Molitoris BA. Quantitative intravital microscopy using a generalized polarity concept for kidney studies. Am J Physiol Cell Physiol. 2005; 289:C1197-C1208. [PubMed: 16033906]

72. Yu W, Sandoval RM, Molitoris BA. Rapid determination of renal filtration function using an optical ratiometric imaging approach. Am J Physiol Renal Physiol. 2007; 292:F1873-F1880. [PubMed: 17311910]

73. Zimpelmann J, Kumar D, Levine DZ, Wehbi G, Imig JD, Navar LG, Burns KD. Early diabetes mellitus stimulates proximal tubule renin mRNA expression in the rat. Kidney Int. 2000; 58:23202330. [PubMed: 11115066]

74. Zipfel WR, Williams RM, Webb WW. Nonlinear magic: multiphoton microscopy in the biosciences. Nat Biotechnol. 2003; 11:1369-1377. [PubMed: 14595365] 

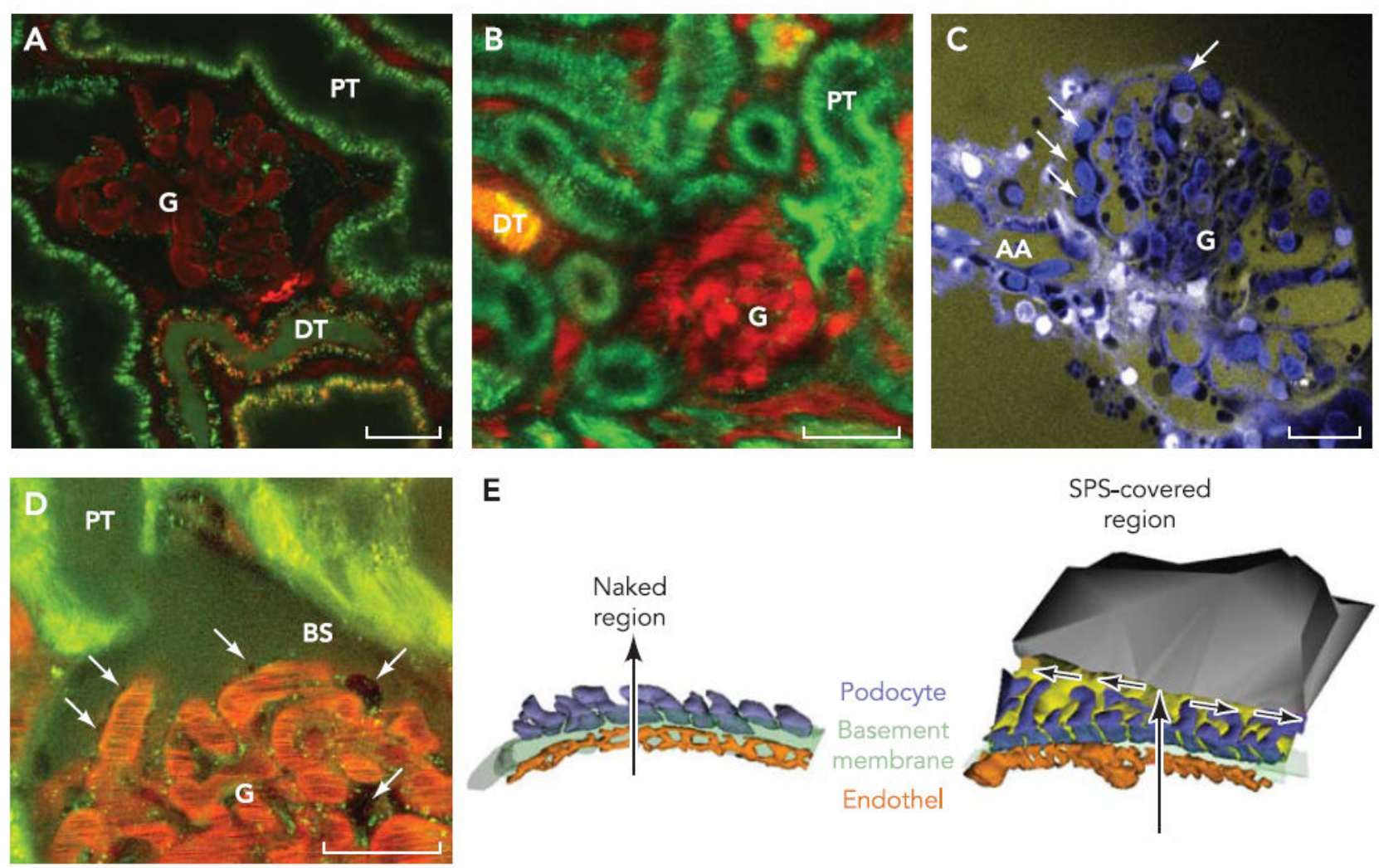

E

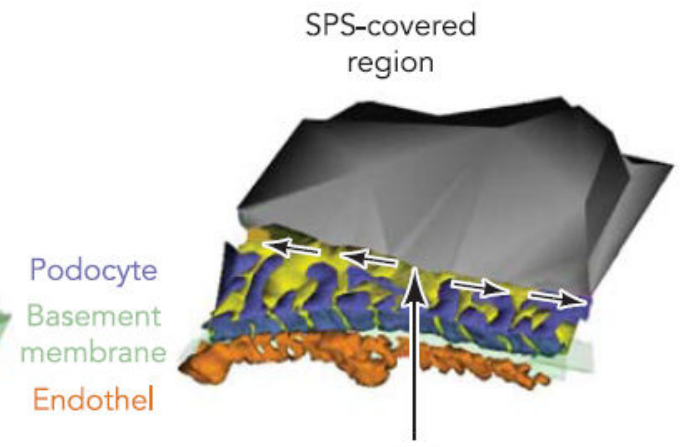

FIGURE 1. Multiphoton imaging of the glomerulus (G) in vivo in various species

In Munich-Wistar-Fromter rats $(A)$ and C57BL6 mice $(B)$ the intravascular space was labeled with 70-kDa dextran-rhodamine B (red) and renal tubules (PT, proximal tubules; DT, distal tubules) with quinacrine (green). In some preparations [in vitro dissected and microperfused rabbit glomerulus $(C)$; rat kidney in vivo $(D)]$, the glomerular filtrate (tubular fluid) was labeled with the small molecular weight $(0.4 \mathrm{kDa})$ extracellular fluid marker Lucifer yellow (LY; yellow) added to the afferent arteriole (AA) perfusate (in $C$ ) or iv (in $D$ ). Cell nuclei were labeled with Hoechst33342 (blue in $C$ ). Due to glomerular filtration, LY labeled the Bowman's space (BS) and outlined cell bodies (arrows) and main processes (arrowheads) of podocytes, which remained unlabeled (dark in $C$ and $D$ ). Note the numerous intracellular vesicles in podocytes close to the glomerular capillaries (green). Scales are 20 $\mu \mathrm{m}$. $E$ : 3D model of the glomerular filtration barrier (GFB) in regions where the GFB is covered by the sub-podocyte space (SPS-covered) or it is not (naked). The SPS lies between the traditional tri-layered GFB and the podocyte cell body. Pink arrows represent fluid and solute movement, which is direct from capillary lumen to the BS in the naked region but occurs via a highly restricted and tortuous route in the SPS-covered region. Figure is modified from Ref. 56. 

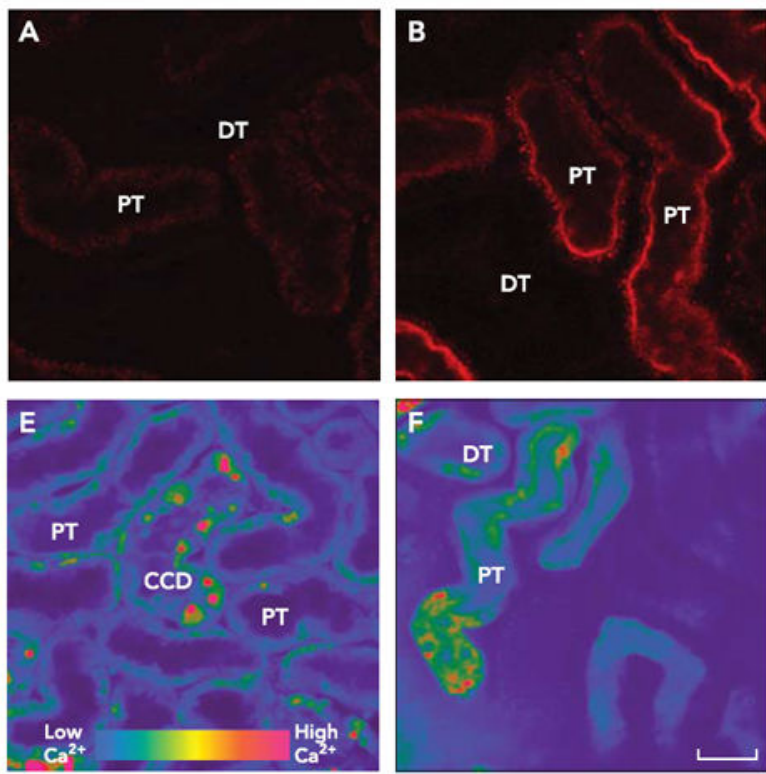
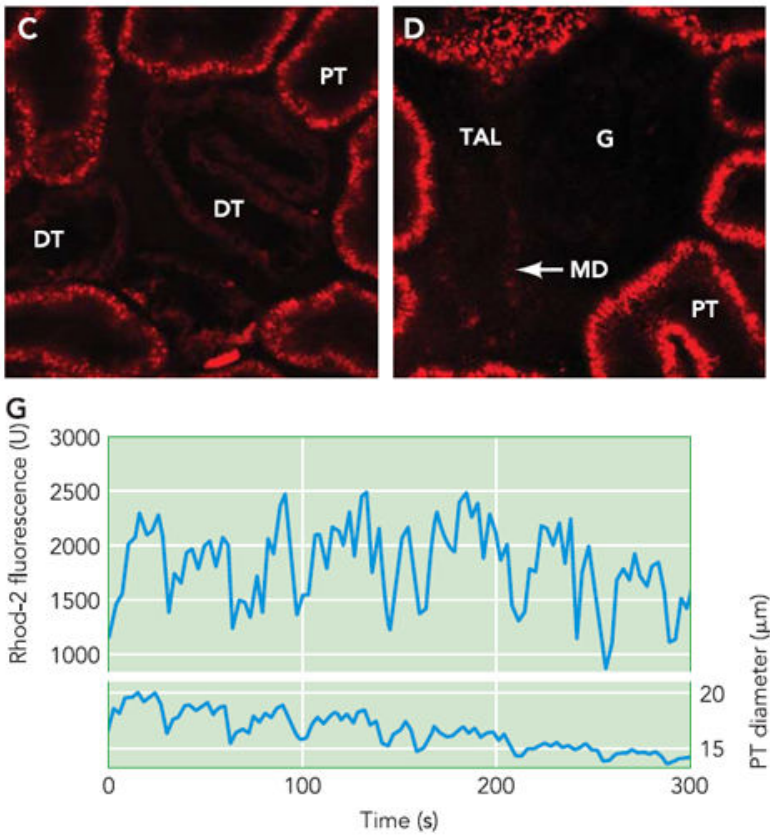

FIGURE 2. In vivo multiphoton imaging of renal tubular functions

$A-D$ : Alexa Fluor 546-labeled siRNA uptake in rat proximal (PT) and distal (DT) tubule segments. Compared with background fluorescence at time $O(A)$, significant levels of AF546-siRNA were detected $(B-D)$ after injection into the carotid artery. Within 2 min of injection, robust siRNA uptake was visible in the PT, mainly at the apical brush border membrane $(B)$, indicating uptake from the tubular lumen. Although lower amounts than that in the PT, siRNA uptake was detected in cells of the DT 15-20 min after injection $(C)$.

Distal nephron siRNA uptake included the macula densa (MD) region of the thick ascending limb (TAL) adjacent to the glomerulus $(\mathrm{G})$ in $D . E$ and $F$ : pseudocolor images of intracellular calcium $\left(\left[\mathrm{Ca}^{2+}\right]_{\mathrm{i}}\right)$ in PT, DT, and cortical collecting duct $(\mathrm{CCD})$ in the intact mouse kidney using Rhod-2 AM injected under the renal capsule. Scale is $20 \mu \mathrm{m}$. $G$ : Rhod-2 fluorescence recording from cells of the PT shows regular oscillations in $\left[\mathrm{Ca}^{2+}\right]_{\mathrm{i}}$ with a slow $(\sim 20-40 \mathrm{mHz})$ and a fast $(100-200 \mathrm{mHz})$ component, which appears to be in phase with oscillations in tubular diameter. 

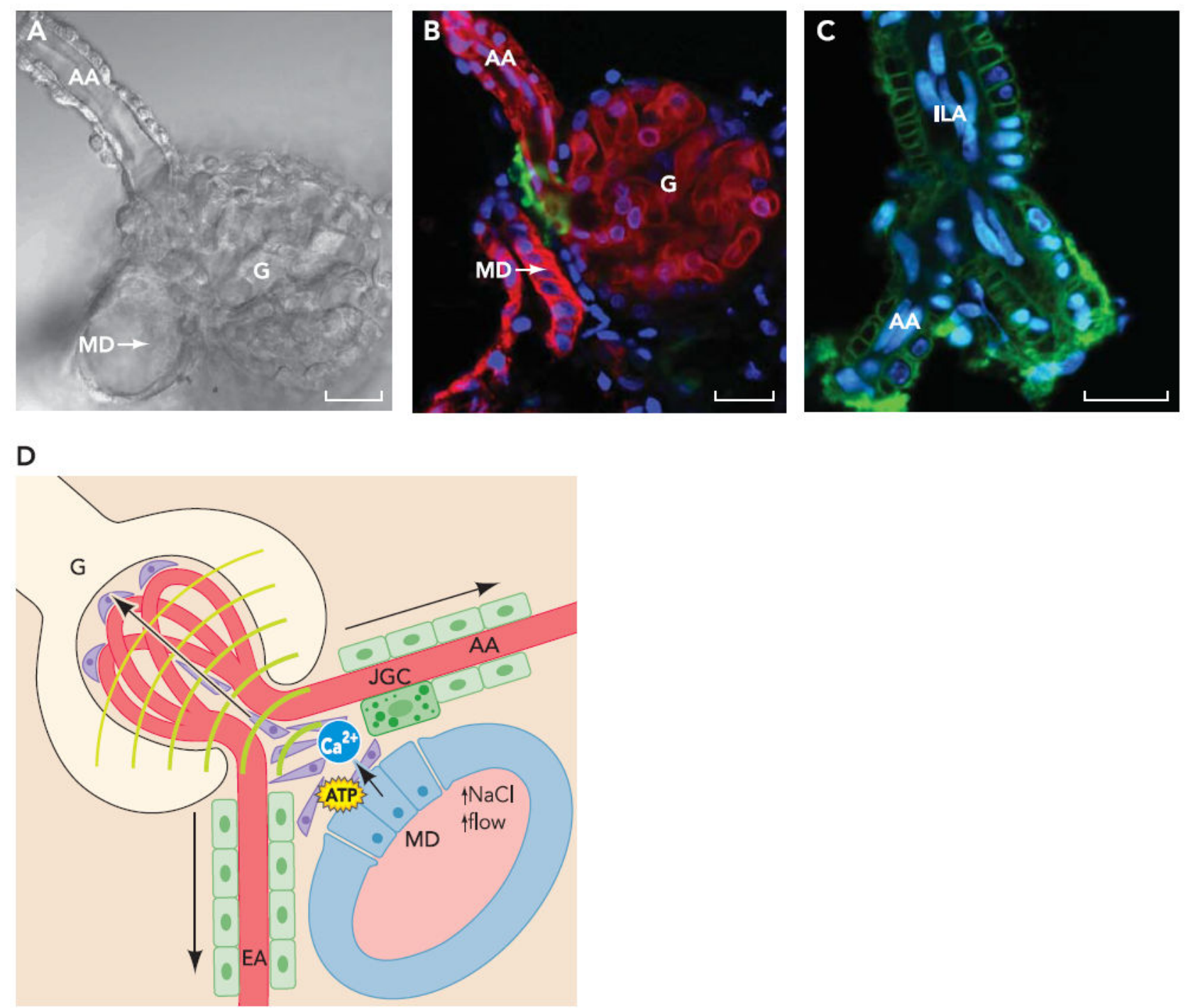

FIGURE 3. Imaging the juxtaglomerular apparatus (JGA)

Transmitted light-DIC $(A)$ and fluorescence images $(B)$ of an in vitro isolated rabbit JGA consisting of the glomerulus (G) and attached, microperfused afferent arteriole (AA) and thick ascending limb containing the macula densa (MD). $B$ : cell membranes of MD cells and the vascular endothelium in AA and $\mathrm{G}$ were labeled with R18 (red), renin granules with quinacrine (green), and cell nuclei with Hoechst 33342 (blue). Figure taken from Ref. 45. C: direct visualization of electrical signals in interlobular artery (ILA) and attached afferent arterioles (AA) in vitro using ANNINE-6, a new, highly sensitive, ultrafast voltage-sensing dye. ANNINE-6 fluorescence is highly cell membrane-specific and intense in vascular smooth muscle cells. Cell nuclei were labeled with Hoechst33342 (blue). Scales in $A-C$ are $20 \mu \mathrm{m} . D$ : components of the TGF calcium wave include ATP release from MD cells in response to elevations in tubular $\mathrm{NaCl}$ and/or flow rate and paracrine, purinergic calcium signaling. Extracellular ATP-induced elevations in mesangial, vascular smooth muscle, and renin producing JG cell $\left[\mathrm{Ca}^{2+}\right]_{\mathrm{i}}$ are then propagated to distant cells of the AA, efferent arteriole (EA), and G away from the MD region, causing cell contractions. 

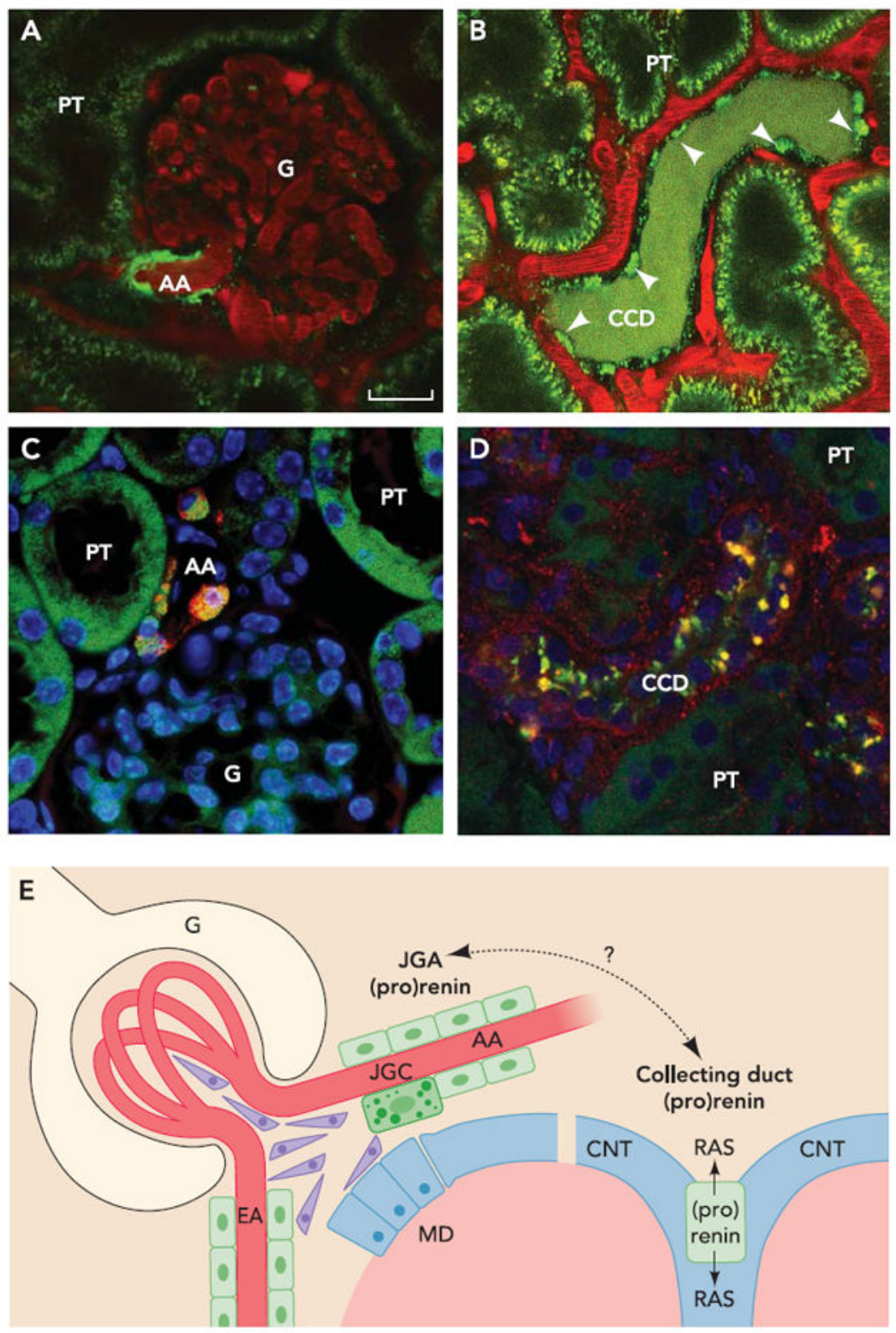

FIGURE 4. The two major sites of intra-renal renin synthesis

Multiphoton imaging ( $A$ and $B$ ), immunofluorescence $(C$ and $D$ ), and schematic drawing $(E)$ of the renin-producing juxtaglomerular apparatus (JGA) and the collecting duct (CD). Control $(A$ and $C$ ) and STZ-diabetic rat kidneys ( $B$ and $D$ ) are shown. $A$ and $B$ : a dextranrhodamine $\mathrm{B}$ conjugate $(70 \mathrm{kDa}$ ) labeled the intravascular space (plasma) red and quinacrine identified JGA renin granules in the terminal afferent arteriole (AA). Note the abundance of quinacrine staining in the bulging apical aspects of $C D$ principal cells in diabetes (arrows in $B$ ). Bar is $20 \mu \mathrm{m}$. $C$ and $D$ : renin immunofluorescence (red) of in vivo quinacrine-labeled (green) rat kidneys. Colocalization (yellow) demonstrates that the majority of quinacrinelabeled vesicles in both the JGA and CCD contain renin. $E$ : regulation and interaction between JGA and CCD (pro)renin synthesis needs further study. G, glomerulus; PT, proximal tubule; $\mathrm{CCD}$, cortical collecting duct; $\mathrm{MD}$, macula densa; $\mathrm{EA}$, efferent arteriole; 
CNT, connecting tubule; RAS, renin-angiotensin system. Figure modified from Ref. 41 with permission from Oxford University Press. 
A
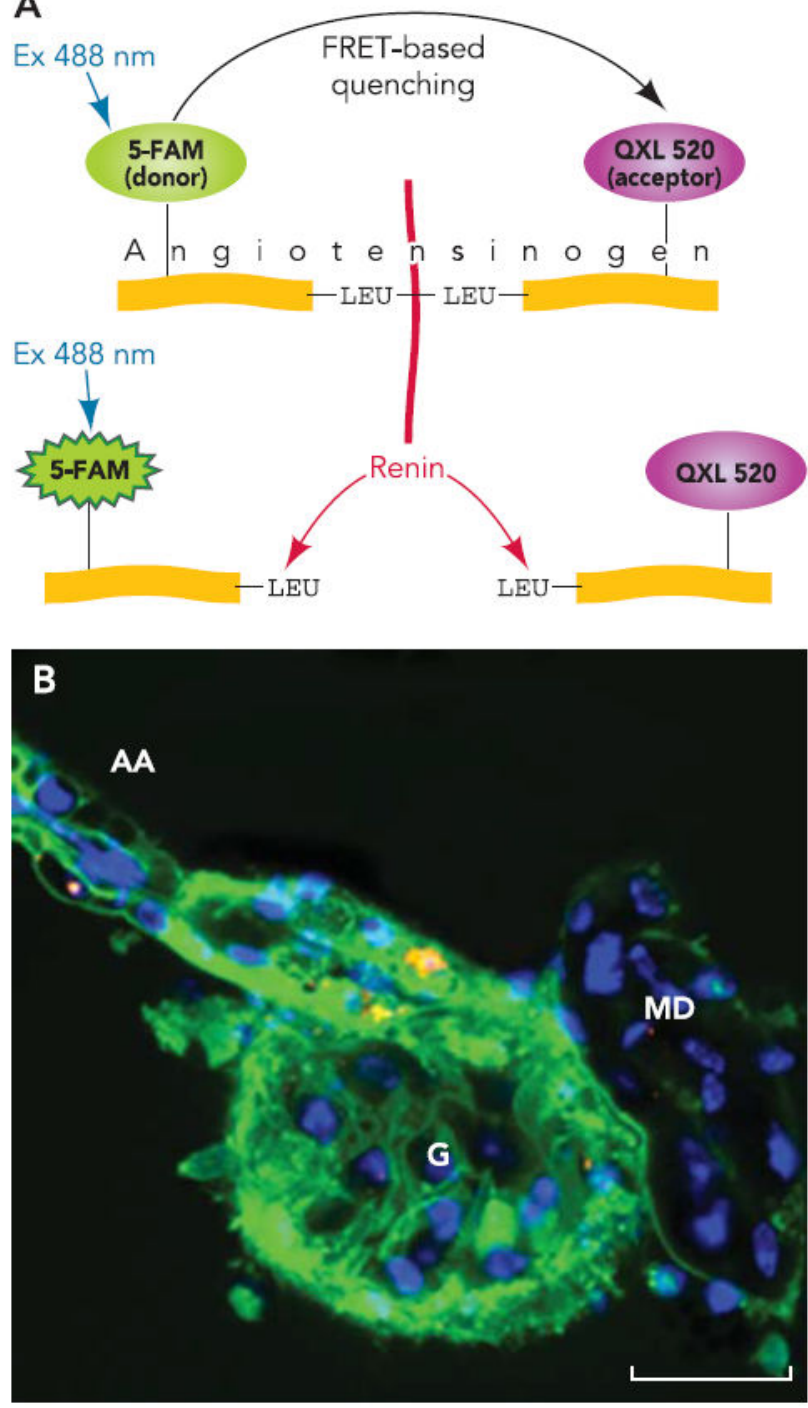

FIGURE 5. Direct visualization of renin activity

A: illustration of the FRET-based fluorogenic renin substrate (AnaSpec, San Jose, CA), which contains a pair of donor-acceptor fluorophores connected by a sequence (decapeptide) of rodent angiotensinogen, including the renin cleavage site at the Leu-Leu bond. In the absence of renin activity, the donor (5-FAM) fluorescence is quenched by the acceptor molecule (QXL 520) due to their close proximity and fluorescence resonance energy transfer (FRET) between them. However, upon cleavage into two separate fragments by rat or mouse renin, the fluorescence of 5-FAM is recovered and can be monitored at excitation/ emission $=488 / 520 \mathrm{~nm}$ (green). $B$ : fluorescence imaging of renin enzymatic activity (green) in the living kidney tissue. A freshly dissected, in vitro microperfused JGA preparation was loaded with LysoTracker-Red that labels renin granular content (red) and incubated with the fluorogenic renin substrate in the bath (green). Nuclei are labeled blue with Hoechst 33342. Note the intense, membrane-bound labeling indicating renin activity in the terminal part of 
the afferent arteriole (AA), in the glomerulus (G), and at the base of macula densa (MD) cells. 